\title{
The Influence of Fashion, Popularity and Custom on Consumer Behavior
}

\author{
Zhao Lunan ${ }^{1, a, *}$, Jin Shui ${ }^{1, b}$ \\ ${ }^{1}$ Business School, Beijing Institute of Fashion Technology, Chaoyang District, Beijing, China \\ a 1056812737@qq.com, binshui@126.com
}

Keywords: popular culture, Hallyu, fashion, consumer behavior analysis

\begin{abstract}
With the development of economy, the pursuit of people is becoming more and more diverse, and there are more and more factors influencing people's purchase behavior. Business marketing methods will also be more diversified. These marketing methods are undoubtedly using a variety of ways to suit the tastes of consumers. There are many factors that influence consumers' buying behavior. The purpose of this paper is to explore the influence of popular, fashion and custom on consumer behavior, so as to get some inspiration.
\end{abstract}

\section{Introduction}

Diversification of consumer behavior comes from social progress and people's thought progress. People are satisfied with the basic physiological needs, and now are more inclined to pursuit lifestyle. When looking through magazines, we will find someone would spend two months' salary on something they take a fancy to or someone swipe their credit card to buy a jacket the same style as their favourite star's. Chinese people will buy many gifts during the Spring Festival. These consumer behaviors are not just to pursue the physiological needs, but to pursue people's spiritual needs. When a lady wears skirt that she had seen in the magazine, she will feel satisfied. When someone wears a jacket the same style with his idol's, he will feel so close between himself and his idol. When people buy decorations or gifts with their families for the holidays, they will be feeling full of happiness. Nowadays, most people do not need to run around for food and clothing, they pursuit the spiritual needs naturally. This paper mainly analyzes the influence of popular, fashion and custom on consumer behavior.

\section{The Influence of Fashion on Consumption Behavior}

Fashion is a life specifications or lifestyle what spread in society or a universal group on certain period of time and it represents a way of life and behavior. Due to the interaction of many people, fashion spread to all areas of daily life quickly. It can be said, as the name implies, fashion is "time" and "respect". In this minimalist sense, fashion is a lifestyle what some people advocating in a short time. It is a social phenomenon, but also a historical phenomenon and psychological phenomenon [1].

Fashion is not only reflected in the dressing, it is reflected in all aspects of life. In terms of clothing, people like luxury brands, or the distinctive and personalized clothing. In terms of Food, people not only pursue food taste, but also pursue environment and appearance of a restaurant. In 
terms of living, people not only require comfortable, but also like to decorate their own room through different colors. In terms of traffic, people not only pursue speed, but also a beautiful appearance or auspicious car number. These reflect people's pursuit of personality or fashion. The following analysis of consumer behavior about the pursuit of fashion is divided into two aspects.

\subsection{The Inner Demand of Consumer}

Everyone's pursuit is different, so everyone's personality is different, which makes each person choose different commodity to express different emotions and to meet their own aesthetic. Great design has been given its unique spirit. Consumer is also based on this spiritual to select commodity. When people reach a certain point, people will have the desire to purchase. The real fashion is a lifestyle of follow your heart. For example, royal aristocrats like to wear long skirts to express elegance, hip-hop people like loose clothing to express the broad-minded uninhibited attitude towards life, and like tattoo to express the attitude of the pursuit of freedom.

\subsection{The External Needs of Consumers}

Human are social animals. Everyone has his own friends. In this social group, people express some vague information that they want to expose though the external clothing or furniture decoration, etc. At the same time, the pursuit of fashion is helpful to integrate into a new group.On the other hand, people will influence each other in this social group. In this time people will meet the Aesthetic of this group to purchase something.

\section{The Influence of Popular Culture on Consumption Behavior}

Popular culture is a kind of social culture which spreads through the advanced media tools, the participation about the majority of the society and the performance in the form of material or nonmaterial, and reflects the people's psychological condition and value orientation[2]. Popular culture has a variety of presentation forms, such as TV series, pop music, and internet celebrity and so on. Popular culture promotes the sale of commodity in varying degrees. Next, we take a case to analyze.

\subsection{Case Description}

Asia is increasingly feeling the phenomenon of hallyu, a newly coined term referring to the increase in popularity of South Korean culture that has been flooding other countries since turn of the century. The first time China felt of it was in 2000, when the TV series Autumn in My Heart aired. In 2014, My Love from the Star boosted sales of fried chicken amid the bird flu crisis, because the female protagonist said she adored "beer and fried chicken" as her favourite food when the first winter snow began to fall. The female protagonist's lipstick or even a global sold out. Popular culture has brought amazing purchasing power.

\subsection{Consumer Behavior Analysis}

The groups of Korean audience are mainly women. The purchasing power of Hallyu is also driven by women. So we analyze women's consumer behavior.

\subsubsection{The Pursuit of Beauty}

Women, especially young women, like the pursuit of fashion and the performance of themselves, and desire for beauty. They always ignore the price, function and other aspects. They have a desire to buy more commodities for the pursuit of beauty. So they follow the trend from Korean popular culture, such as the hairstyle, clothes, leisure and entertainment and so on.

\subsubsection{Imitation Behavior}

They want to be consistent with the popular style in order to achieve social recognition, adapt to 
the rapidly changing social life, to obtain a sense of security, so as to achieve psychological balance. So they will imitate the popular style.

\subsubsection{Celebrity Effect}

Women tend to feel more reliable and convincing about the words and deeds from the authority, so more likely to accept hints from similar groups. Women are more concern about the words and deeds from celebrities or stars, and more willing to accept their behavior. So they have a higher degree of trust and a strong desire to buy the goods of celebrity endorsement.

\subsubsection{Unconscious Memory}

When women watch the Korean drama, they will unconsciously remember the furnishings in Korean drama, the makeup of the protagonist, clothing and diet and so on. And thus it will unconsciously affect the daily life of these women. They will unconsciously imitate. For example, they like to buy some clothes which appeared in Korean drama.

\section{The Influence of Custom on Consumption Behavior}

Different countries have different cultures. Different cultures lead to different consumer behavior in different countries. Take Chinese traditional culture as an example, we analyze the influence of traditional customs on consumption behavior. When it comes to traditional customs, it is naturally thinking about a series of activities such as dragon boat racing, eating mooncake and eating dumplings and so on. These activities are precious treasures left by 5,000-year traditional culture. What traditional culture left is not just these festivals, but also affected the behavior of the Chinese people, lifestyle and so on.

\subsection{The Characteristics of Chinese Traditional Culture}

\subsubsection{Attention to family}

Chinese people always pay attention to their families since ancient times, advocating collectivism and the spirit of collective devotion. The culture of Confucius and Mencius requires people to be kindness, self-discipline and higher loyalty and keep up good relations with their peers. In addition, traditional culture requires us to respect the elderly, respect the dignitaries. In society, the concept of status and hierarchy still keep popular support. If the choice of individualism or collectivism is required, almost all the literature points out that traditional culture places greater emphasis on collectivism and emphasizes the cooperation of human-to-human.

\subsubsection{The Doctrine of The Mean Culture}

The world outlook of traditional Chinese thought is a harmonious world view, which stresses the harmony and unity of the whole world. Heaven, earth and human is a harmonious whole. In Song Dynasty, Confucianism advocated the unity of all things, to treat the world with benevolence. This harmonious world view requires people to follow the principle of benevolence and loyalty to deal with the relationship between people, emphasizing the love, never do to others what you would not like them to do to you. Confucius asked to be full of love between people, to "have Yuli written for the people, has been reached and want to reach people".

\subsection{3. "Relationship" Culture}

Chinese people attach importance to the exchange of friendship between human and human, contempt for materialism. Since ancient times, there are some proverbs, such as "reciprocity" and "courtesy on one side only lasts not long". People regard "relationship" as a kind of social capital which is only lower than knowledge and technology. Most of the time, people can achieve their target through "relationship" that material exchange cannot be done. "Relationship" can be said 
that people deliver goodwill and sincerity each other with fully guarantee mutual trust.

\subsection{4. "Face-assertion" Culture}

The ancients washed and dressed up every day, looked and checked themselves in front of the bronze mirror, and then started one day's work. Mr. Lu Xun wrote an article to analyze the "face". He believes that there are two types of "face", one is that each identity has a "face", the other one is different with the general people.

\subsection{The Characteristics of China's Consumer Behavior}

\subsubsection{Consumer Behavior in A Popular Style}

Chinese people like follow other people to do something, this is not a secret. In terms of consumption, Chinese consumers like to buy something that other people like. In e-commerce platform, people are more interested to buy something with the higher of the volume of goods sold. When consumers see a dress worn by their idol, consumers will buy this dress in order to imitate their idol.

\subsection{2. "Relationship" Consumption}

"Relationship" consumption is a prominent characteristic of consumer behavior in China. Take the "high price mooncake" incident as an example, the purpose of consumers buy this mooncake is give sfriends gifts. The more expensive mooncakes, more "Face-assertion", and reflect the more trust of friendship. So gift sales in the Chinese market much better than gift sales in Western market, such as wine, mooncake, and tobacco and so on.

\subsubsection{Consumption Choices Based on Family}

Traditional family ethics follow "respect the old and cherish the young", "filial piety" and so on in China. This allows Chinese consumers to pay more attention to other family members when making purchase intentions. Such as purchasing clothing for parents, buying toys for their children, and so on, this is a large proportion of purchases for women in China. When making consumer choice, those women not only consider their own needs, but also consider the needs of their family. For example, Chinese people prefer to save money, while Westerners tend to lend to banks.

\subsubsection{The Influence of Traditional Customs on Consumption Behavior}

When the traditional festival is coming, people like to buy something to make themselves feel happiness. For example, people will prepare a new dress for themselves at the time of the Spring Festival. In addition, Chinese people like red, they believe red represents auspicious and festive. Therefore, the Chinese people like to buy red goods in the festival.

\section{Conclusions}

This paper analyzes the influencing factors of consumer behavior from three aspects. First of all, the pursuit of fashion reflects the individual to pursue individuality and lifestyle, which is mainly driven by internal and external factors. Secondly, it is clear that people are affected by many psychological factors to make purchasing decisions by analyze the influence of hallyu. Finally, it analyzes the impact of Chinese traditional culture on people's consumption behavior. We realize that the influence of fashion, popular culture and traditional custom on consumer behavior cannot be underestimated.

\section{Acknowledgements}

I would like to express my heartfelt gratitude to my tutor, associate professor Jin Shui, for his constant encouragement and guidance. He has walked me through all the stages of the writing of 
this thesis. Without his consistent and illuminating instruction, this thesis could not have reached its present form.

\section{References}

[1] Wang Ting. We Need Young Blood[J]. China Textile. 2011(10)

[2] Wu Wei. The Essence of Fashion Lasts Forever[J]. China Today. 2011(10)

[3] Wanzy Wang, Flora Zhao. Fashion Week Illumes Fashion Life[J]. China Textile. 2012(05)

[4] Hyunju Song. Basic research for developing a Korean pronunciation self-study program for Chinese leaners[A]. 2015 